\title{
Customizing Europe: Transposition as bottom-up implementation
}

This is the accepted version of:

Thomann, E. 2015. Customizing Europe: Transposition as bottom-up implementation. Journal of European Public Policy 22(10): 1368-1387.

\begin{abstract}
European Union (EU) implementation research has neglected situations when member states go beyond the minimum requirements prescribed in EU directives (goldplating). The top-down focus on compliance insufficiently accounts for the fact that positive integration actually allows member states to transcend the EU's requirements to facilitate context-sensitive problem-solving. This study adopts a bottom-up implementation perspective. Moving beyond compliance, it introduces the concept of 'customization' to depict how transposition results in tailor-made solutions in a multi-level system. The study analyzes the hitherto unexplored veterinary drug regulations of four member states. Using fuzzy-set Qualitative Comparative Analysis and formal theory evaluation, this paper assesses how policy and country-level factors interact. Results reveal the countries' different customization styles. The latter simultaneously reflect the interplay of domestic politics with institutions, and the 'fit' of EU regulatory modes with domestic, sectoral interventionist styles. Compliance approaches cannot fully explain these fine-grained patterns of Europeanization.
\end{abstract}

KEYWORDS Europeanization; Gold-plating; Qualitative Comparative Analysis; Theory Evaluation; Transposition. 


\section{Introduction}

'The European experience shows that far-reaching economic integration can be achieved without suppressing cultural diversity and legitimate differences in national preferences.' Giandomenico Majone (1999: 309).

This paper analyzes how European Union (EU) member states adapt EU directives to domestic contexts during transposition. European integration entails that member states transfer their autonomy to a common institutional framework to allow for common policies. To account for domestic circumstances, EU directives then delegate some decision-making processes to the transposing countries (Treib 2014). The resulting diversity of domestic policies is studied by legal Europeanization scholars, who view transposition as a mechanism by which EU law impacts domestic regulations (Börzel and Risse 2012; Töller 2010). EU implementation research has strongly emphasized the degree of (non-)compliance with EU directives, the timeliness and correctness of transposition, the amount of non-compliance and transposition rates (Toshkov 2010). Despite their variety and sophistication (Angelova et al. 2012), the concepts and explanations that have been proposed for transposition outcomes commonly focus on compliance, asking whether or not the translation into domestic law conforms to the EU directive (Treib 2014).

Some argue that 'this focus insufficiently captures the implications of member states being part of a multi-level system' (Schmidt 2008: 299). The question of compliance corresponds to a top-down view of implementation as hierarchical guidance. Although highly relevant, this approach 'tends to prejudge the EU as the main source of domestic change' (Börzel and Risse 2012: 2). By contrast, bottom-up perspectives view implementation as decentralized problemsolving. Europeanization becomes the application of common solutions to shared problems, 
tailor-made to domestic circumstances (Pülzl and Treib 2007). The analytic focus shifts toward the "conditions [under which] directives do or do not allow for continuing national heterogeneity' (Töller 2010: 429) to facilitate context-sensitive problem-solving.

When member states go beyond the minimum requirements of European legislation - named 'gold-plating'- they are typically considered to hamper the enabling of markets. According to a widespread 'no gold-plating' policy, implementation should be restricted to what is necessary to comply with the EU's minimum requirements (Morris 2011; Voermans 2009). Notwithstanding this, market-correcting measures allow member states to go further than the EU's minimum requirement (Jans et al. 2009). Reconciling integration with differences in national preferences fosters the EU's capacity to respond to the countries' cultural diversity (Majone 1999), and enables countries to respond to domestic circumstances. The top-down focus on compliance and negative integration neglects this bottom-up aspect of the 'European experience' (ibid). Previous studies have therefore not addressed this phenomenon extensively (Voermans 2009).

This study moves beyond compliance (Schmidt 2008) and asks: how and why do fully compliant countries 'customize' EU directives? As the focus is on customization, this is hence not a compliance study. Customization refers to the additional regulatory density and stringency of the domestic regulations compared to the market-correcting EU directive (Knill et al. 2012). The paper expands Europeanization research to a new sector (Angelova et al. 2012). It draws on original data on veterinary drug regulations in France, the United Kingdom (UK), Germany and Austria as comparable and likely cases for customization. These countries all comply with the EU's rules to ensure the safety and exportability of their food products (Sager et al. 2011). However, the domestic regulations differ considerably in the degree to which they transcend the EU directive.

Using fuzzy-set qualitative Comparative Analysis (fsQCA) (Ragin 2000) to account for 
interactions, several propositions derived from compliance arguments on how the interplay between policy and country-level factors affects customization are formally evaluated. Results show that discretion matters and specify the conditions under which institutions mediate the consideration of domestic players' interests during transposition. Simultaneously, countries reinterpret EU directives depending on the 'fit' of EU regulatory modes with domestic, sectoral interventionist styles. Compliance approaches cannot fully explain these more finegrained Europeanization patterns.

I now define the novel 'customization' concept. Subsequently, I discuss prominent implementation arguments to derive conditions for customization and hypotheses about their interplay. I then outline the research design before presenting my results, based on which I evaluate the hypotheses and conclude.

\section{Defining customization}

Diverse approaches of problem-solving are an intended result of decentralized implementation structures (Majone 1999; Treib 2014). However, the remaining differences within the boundaries left by EU law have seldom received attention as a transposition outcome (Falkner et al. 2005: 140-159; Töller 2010). Gold-plating refers to the 'non-literal', as opposed to 'literal', interpretation of EU directives (Steunenberg 2007). It denotes all instances where at the national level more is being regulated than strictly required, by extending the scope, not taking full advantage of derogations, retaining higher domestic standards or implementing 'too' early (Jans et al. 2009). Case study evidence from the Netherlands and the UK suggests that environmental directives are rarely gold-plated (Jans et al. 2009; Morris 2011; Voermans 2009).

The term gold-plating has two weaknesses. First, it blurs the conceptual distinction between 
changes in policy outputs concerning the regulatory density or the policy's stringency (Knill and Lenschow 1998; Knill et al. 2012). Second, by including both the early implementation and the non-literal interpretation of EU directives in the definition, gold-plating has not been clearly demarcated from non-compliance. Gold-plating thus retains a top-down connotation of unnecessary and potentially problematic 'over-implementation' (Falkner et al. 2005; Kaeding 2008; Mastenbroek 2005).

However, in market-correcting domains, minimum harmonization essentially means that the member states may further interpret the EU's minimum requirement, except under conditions of full standardization (Jans et al. 2009; Voermans 2009). From a bottom-up perspective, countries 'customize' EU directives. Customization occurs when compliant countries use their leeway to adapt EU rules to domestic particularities. The transposing body might also consciously leave pre-existing domestic policies unchanged, if they conform to the EU policy (Treib 2014). Customization means the degree to which the domestic regulations complement the EU directive with more or stricter rules than required. Customization can manifest itself as gold-plating (except for early implementation), but has two dimensions (Knill et al. 2012). Customization can refer to the formal regulatory density of the domestic regulations. Density means the amount of additional rules that concretize the EU directive ('level of detail'; Versluis 2003). Stringency depicts the substantial additional restrictiveness of the domestic rule. Restrictiveness means the number of additional restrictions of the substantial freedom left to policy addressees in personal, substantive, or temporal scope (Knill et al. 2012). Transposition studies usually aggregate outcomes at the level of directives (Angelova et al. 2012). However, directives regulate diverse issues, which typically address different target groups and subsectors and are transposed into different national legislations, sometimes by several legislative bodies. Hence, single issues are a more relevant unit of analysis than directives (Toshkov 2010). I use the terms 'regulations' or 'policies' interchangeably to 
denote a set of techniques by which public actors 'wield their power in attempting to ensure support and effect or prevent social change' concerning a specific issue (Vedung 1998: 21). Extensive customization does not indicate non-compliance with EU law. Customization presupposes full adoption (timely or not) and then depicts the additional density and /or restrictiveness of the domestic regulations. Member states just go further than the EU in applying a market-correcting solution - for example, by additionally restricting the use of antibiotics for livestock to fight antibiotic resistance. Similarly, the limited customization of EU directives does not imply 'more' compliance. Instead, this entails that EU minimum requirements were simply adopted without changes - for example, by complying with, but not transcending the EU's minimum requirement to not use more antibiotics than needed for an adequate treatment.

There is at best inconclusive evidence that the substantive fit of European with national policies ${ }^{1}$ dominantly explains domestic responses (e.g., Falkner et al. [2005]; Knill and Lehmkuhl [2002]; Mastenbroek [2005]; Mastenbroek and Kaeding [2006]; Toshkov [2010]; for a different view, see Angelova et al. [2012]; Steunenberg and Toshkov [2009]). The customization concept integrates this insight by conceiving the closeness of domestic policies to the EU template as an outcome rather than an input of transposition. Adapting existing 'goodness of fit' measures to customization, the data point is no longer prior to, but after transposition. I adopt Knill and Lehmkuhl's (2002) distinction of 'institutional compatibility' to measure the extent of occurred (as opposed to required) domestic changes in policies (as a subset of domestic arrangements) in response to EU policies. Each domestic regulation is classified according to whether changes in comparison to the EU policy are absent (0), relatively moderate (1) or extensive (2) concerning a) density and b) intensity. Moderate changes usually entail 1 , and extensive, 2 or more changes. ${ }^{2}$

Austria for instance concretizes the abovementioned EU requirement by restricting the use of 
antibiotics to maximally one month (1 additional rule, 1 additional restriction). These two dimensions are added into a customization index. Only with extensive changes in both dimensions, customization is fully extensive (4). For customization to be more extensive than limited, at least moderate changes in both dimensions, or moderate changes in one dimension, but extensive changes in the other, are required ( 2 or 3$)$. If only one dimension entails moderate changes (1), then customization is more limited than extensive. Without any changes, customization is fully absent (0).

\section{Explaining customization}

Top-down perspectives assume a direct link between European policies and domestic outcomes (Pülzl and Treib 2007). Bottom-up arguments have shifted the attention to countrylevel factors (Mastenbroek and Kaeding 2006). Recent studies emphasize the complex causal interactions of structural and agency-related factors behind transposition (for recent overviews see Angelova et al. [2012]; Perkins and Neumayer [2007]; Toshkov [2010]; Treib [2014]). In this third tradition, I discuss how the interplay of both policy and domestic factors might affect customization (Di Lucia and Kronsell 2010; Steunenberg 2007). For the sake of cumulativeness, I revisit prominent compliance arguments potentially relevant for customization that received considerable and conclusive empirical support. Results will show whether they treat the distinct features of customization well.

\section{EU regulatory mode}

Regulatory leeway matters for implementation (Steunenberg and Toshkov 2009; Töller 2010). Knill and Lenschow (2003) distinguish EU governance modes through their level of obligation and the amount of discretion granted. Referring to the latter, inflexible instruments 
in (by definition obligatory) directives entail detailed substantive or procedural rules.

Conversely, flexible instruments in directives are legally binding, but define only broad goals, offer exemption and derogation possibilities or several policy options. Flexible instruments grant implementers more discretion than inflexible instruments to respond to domestic problem constellations (Treib et al. 2007). Vaguer measures provide domestic policy makers with opportunities to realize their interests. EU regulatory modes can thus be unresponsive to domestic adaptation (inflexible instruments), or display differing degrees or responsiveness (flexible instruments). Discretion intuitively appears a prerequisite for customization:

H1: A responsive EU regulatory mode is a necessary condition for extensive customization.

H2: Inflexible instruments are typically not or hardly customized. ${ }^{3}$

However, flexible instruments might result due to member states defending their status quo during EU negotiations. Domestic policy diversity would then produce flexible instruments, and not vice versa. In contrast, the EU decision-making processes for the three directives under analysis were characterized by low politicization and a widespread need for harmonization. ${ }^{4}$

\section{Issue salience}

Given the enormous number of EU directives, domestic actors pick and choose where to focus their attention (Versluis 2003). Less salient regulations are ignored (Knill and Lenschow 1998; Toshkov 2010) and thus rather not customized. Salience refers to the visibility of and the importance attached to a topic, the main indicator being public attention. Salience can indicate either the high importance of a policy or its political contestation (Versluis 2003). 


\section{Domestic resistance}

EU policies may lead to political struggles between domestic players (Falkner et al. 2005; Knill and Lenschow 1998; Mastenbroek 2005; Treib 2014). Domestic opposition (Steunenberg 2007; Toshkow 2010) should foster differentiated domestic rules designed to meet the stakeholders' needs. Or this can lead to more restrictive rules, if the opposition deems the EU policy too lax. Resistance means that at least one main target group with some power to influence domestic policy-making with resources and/or lobbying activities opposes the EU policy.

\section{Institutions}

Institutional veto points are stages in the decision-making process on which, and institutional veto players individual or collective actors whose, agreement is formally required for transposition. Such institutions empower or constrain administrative, societal and political actors to pursue their interests (Mastenbroek 2005; Treib 2014; Tsebelis 1995). This should facilitate an extensive customization (Falkner et al. 2005). Policy-specific consultation processes without parliamentary involvement serve the same function (Steunenberg 2007; Töller 2010). I define veto points as the combination of the degree of decentralization (Mastenbroek and Kaeding 2006; Versluis 2003), bicameralism, and corporatism. Since transposition often bypasses the political arena, corporatism becomes as important as decentralization and bicameralism.

Arguments that 'bring domestic politics back in' (Mastenbroek 2005: 1110) emphasize the interplay of domestic interests and institutions. Domestic opposition can only be influential when institutions do not effectively shelter the policy-making body from societal demands 
(Haverland 2000; Steunenberg and Toshkov 2009; Toshkov 2010). Both opposed stakeholders and institutional veto players are more likely to promote their interests in the context of salient issues (Angelova et al. 2012: 1284; Mastenbroek and Kaeding 2006: 341). A 'domestic politics' hypothesis follows:

H3: Salient issues are typically customized extensively when they are opposed domestically and numerous veto points or veto players prevail.

\section{Domestic, sectoral interventionist styles}

Administrative bodies as policy makers conduct a large part of the transposition process (Steunenberg 2007; Töller 2010). 'Constructivist' arguments assume that these bodies follow a logic of appropriateness, hence acting in accordance with rules and practices that are socially constructed and anticipated and associate particular identities to particular situations (March and Olsen 1998). EU policies may or may not 'fit', i.e. be compatible with domestically held (regulatory) identities. Local administrations (re)interpret the overarching norm to ensure that it fits their identities (Börzel and Risse 2012; Falkner et al. 2005; Mastenbroek 2005; Mastenbroek and Kaeding 2006).

Mastenbroek and Kaeding (2006: 344-45) argue that when following a logic of appropriateness, member states conform to habits, i.e. patterns of behavior acquired by frequent repetition. What matters is thus 'not the fit [of EU policies] with the status quo, but the fit with the domestic belief system underlying that status quo' (ibid: 345). Referring to the latter, Perkins and Neumayer (2007) suggest that the policymaking preferences of national governments matter (see also Di Lucia and Kronsell [2010]; Treib [2014: 18]). In my analysis I am particularly interested in patterns of established state-society relations (Treib 2014: 24). 
Domestic, sectoral interventionist styles represent such habits concerning the relationship between state and individuals, which manifests itself in the use of coercion through policy instruments (Sager 2009).

Vedung (1998) distinguishes policy instruments formally by the degree of authoritative force exercised by the governor on target populations. 'Sticks' are authoritative regulations where the governed is obligated to comply. 'Carrots' are non-compulsory (dis)incentives for an action by allocation or deprivation of material resources. 'Sermons' are voluntary means of information. The countries' sectoral interventionist styles are expressed through the average degree of coerciveness of, i.e. the relative prevalence of sermons, carrots and sticks in, the transposing domestic veterinary drugs regulations (Sager 2009). In highly Europeanized countries, domestic interventionist styles partly reflect, but can go greatly beyond the degree of coerciveness of the EU's minimum requirements. Similarly, the sector under analysis was largely unregulated domestically before the EU directives were issues. The underlying measurement hypothesis is that the countries' habits of exerting coercion are relatively stable over time; thus, present levels of coerciveness also reflect general tendencies of coerciveness (March and Olsen 1998).

EU regulatory modes, customization and domestic, sectoral interventionist styles reflect the degree of state intervention as 'the quintessence of government' (Sager 2009: 537) from differing angles. The flexibility of EU instruments concerns the relationship between the EU and both member states and target groups. The interventionist styles are an aggregated measure of national policy-making preferences, referring to the formal question whether the final target groups have a choice to comply or not. Finally, the restrictiveness dimension of customization captures the substantive, additional stringency of single domestic regulations as compared to the directive. Domestic, sectoral interventionist styles and customization are thus not tautological concepts. ${ }^{5}$ For instance, all countries define obligatory 'sticks' for 
documenting veterinary drug dispensing. However, these sticks are not more restrictive than the strict EU template.

Regarding the degree of state intervention, EU regulatory modes can more or less 'fit' domestic, sectoral interventionist styles. This (mis)fit might affect customization. Flexible instruments are minimally authoritative. By contrast, a coercive interventionist style imposes a high degree of obligation on the governed. Hence, to reduce the distance between the two, flexible instruments might be customized into a more restrictive version. Conversely, a noncoercive interventionist style favors rules that only minimally limit individual choices. Since inflexible instruments already pose considerable limits on individual freedom, adding restrictiveness would not fit the country's interventionist style. Two last hypotheses capture the logic of appropriateness:

H4: Countries with a coercive interventionist style typically customize flexible instruments extensively.

H5: Countries with a non-coercive interventionist style typically customize inflexible instruments to a limited degree.

\section{Data}

The domestic regulations of single issues in a market-correcting sector serve as the units of analysis for customization. I now discuss why the sector of veterinary drugs regulations is illustrative, the policy issues of dispensing and administration are likely cases, and the countries France, UK, Germany and Austria are comparable cases for customization.

Europeanization research needs to expand to new policy sectors (Angelova et al. 2012). Veterinary drug regulations are both under-researched and a particularly illustrative example 
of positive integration. Scandals related to animal diseases like bluetongue and antibiotic resistance have triggered public awareness about the importance of food safety. Veterinary drug regulations crucially correct these failures in the European single market for food products. The regulations ensure animal health and food safety across borders by preventing and managing animal diseases and antibiotic residues in food. Ensuring the exportability of their food products is essential for the countries. Thus compliance with the EU directives, a prerequisite for customization, is generally given (Sager et al. 2014).

Veterinary drugs are dispensed by veterinarians or pharmacies to the end users - veterinarians or livestock farmers - who administer the drug to the livestock. Contrary to marketing authorization or food processing, these 'on the ground' processes do not immediately intersect with the transboundary single markets for pharmaceutical or food products. This makes standardization unlikely and customization likely with these regulations. In this population, all possible cases for customization are analyzed: 13 regulations of dispensing and 6 policies of administration, which are a) regulated in an EU directive, b) not instances of full standardization, and c) distinguishable from other processes. The EU policies (10 flexible and 9 inflexible instruments) stem from three directives: Council Directive 90/167/EEC on medicated feedingstuffs, Directive 2001/82/EC on veterinary medicinal products and Commission Directive 2006/130/EC on the prescription requirements (table B1, online appendix).

The more contextually similar the analyzed countries are, the more potential intervening factors can be controlled for (Rihoux and Ragin 2009). I compare the domestic regulations of Austria, Germany, France and the UK in $2011(\mathrm{~N}=76)$. These countries share a tendency toward low compliance (Falkner et al. 2005), similar regulatory contexts and functional problems. Food safety scandals triggered the relevance of veterinary drug regulations, and livestock farming has a similar significance for agriculture: the value added to the gross 
domestic product by agriculture was between 1 and 4.7, but below EU average in 2000. All domestic regulations analyzed here were subject to extensive revisions since the EU directives were issued (Sager et al. 2011: 301-302).

The original case study evidence for this study was collected for the Swiss Federal Office of Public Health (Sager et al. 2011). Methods comprised an analysis of legal documents, policy documents, secondary literature, telephone interviews and written questionnaires with agents of relevant stakeholder groups and the public administration.

\section{Method}

I apply Qualitative Comparative Analysis (QCA) (Ragin 2000) to identify necessary conditions and sufficient combinations of conditions for customization, subsequently called configurations, scenarios or paths. QCA allows for conjunctural causality, i.e. for the effect of a single condition to unfold in combination with other conditions, as hypothesized. The notion of equifinality then captures that the customization of EU policies may have several, mutually non-exclusive, context-dependent explanations (Perkins and Neumayer 2007). The assumption of causal asymmetry entails that extensive customization can be explained differently than limited customization (Di Lucia and Kronsell 2010; Schneider and Wagemann 2012: 78).

QCA understands variables as sets in which every case has a certain membership. The calibration process entails the definition of anchors for set membership, based on theoretical and substantive knowledge. Fuzzy sets allow for degrees of (non-)membership scores. These can vary between full membership (score 1, e.g. extensive customization) and full nonmembership (score 0, e.g. no customization). The dichotomous difference 'in kind' is indicated by the crossover point (score 0.5 ). Values above 0.5 indicate that a case is more a 
member than a non-member in the set (e.g., rather or fully extensive customization), yet to differing degrees. Values below 0.5 indicate the opposite, e.g., rather or fully limited customization (Ragin 2000).

The calibrated empirical data are then transferred into a truth table, the rows of which represent all logically possible combinations of conditions. If all or enough cases' fuzzy set membership in a truth table row is smaller than or equal to its membership in the outcome, then the row is identified as a sufficient path for the outcome. The logical minimization procedure then reduces the complexity of all sufficient truth table rows to find the shortest possible causal expression for the combinations of conditions that imply the outcome, named solution term (Rihoux and Ragin 2009).

FsQCA allows for certain probabilistic aspects. Consistency expresses the degree to which the empirical evidence is in line with the statement of sufficiency or necessity. Consistency sufficiency can be indicated for truth table rows (raw consistency), single paths of, or the whole solution term. Coverage denotes how much of the observations are explained by the model. Raw coverage expresses how much of the outcome is covered by a single path, solution coverage does the same for the solution term, while unique coverage indicates how much a path covers alone. The basis on which appropriate levels for these measures (from 01) are chosen should be research-specific. Consistency sufficiency should not be below 0.75 . Raw consistency levels were chosen according to 'gaps' in the raw consistency values and the presence of contradictory cases (Schneider and Wagemann 2012: 127f, 143ff). Contradictory cases are 'more in than out' in the set of explanatory factors, but 'more out than in' the outcome set; thus, the explanation was not sufficient for the outcome.

I apply the Enhanced Standard Analysis procedure and rely on the intermediate solution term. I hence make theoretically informed directional expectations for single conditions, and I ensure that no combination of conditions is assumed to imply both extensive and limited 
customization. Online appendix B displays the truth tables, the directional expectations, the complex and parsimonious solution terms, indications on limited diversity, untenable and simplifying assumptions (Schneider and Wagemann 2012: 167-211). Results are illustrated with typical cases; space is too limited to discuss deviant cases.

Online appendix A discusses the measurement and calibration. For CUSTOM, VPO, VPL and COERC, values of 0.05 and 0.95 already indicate full set (non-)membership. Online appendix D contains all databases, the raw data matrix and the fuzzy set scores.

\section{Results}

Administration policies tend to be more salient and disputed, but customized less extensively than dispensing policies. Figure 1 illustrates the diversity of the domestic settings. Values above 0.5 indicate that the specific feature is more often present than absent, and to which degree. The countries display different interventionist styles and 'customization styles'. Austria and France are comparable. The policies typically face a rather low amount of domestic resistance. Austria, as a federal state, has many veto points but few veto players. The opposite is the case in the centralized state of France. In line with the two countries' rather coercive interventionist traditions, the EU policies are rendered slightly more restrictive, but not differentiated extensively.

--Insert figure 1 here--

Germany and the UK provide two almost ideal-typical counterexamples. The federal state of Germany is the only country where veterinary drug issues are highly salient and contested on average. Simultaneously many veto points and players prevail. In accordance with its highly 
coercive interventionist style, Germany most often implements more restrictive domestic rules than necessary and differentiates EU directives. By contrast, in the centralized state of the UK domestic resistance tends to be rather limited and few veto points and players exist.

Consistent with previous evidence (Jans et al. 2009; Morris 2011), the UK more rarely innovatively interprets and sometimes amends EU policies than the other countries, mainly to maintain its liberal regulatory approach that stresses individual responsibility, based on recommendations of good practice.

No single necessary condition for the outcome was found (table B2, online appendix). Hypothesis 1 is thus refuted. Table 1 presents the four paths that imply extensive customization. I use capital letters if a feature is present and lower case letters for its absence. The * sign signifies 'AND', i.e. that several factors occur in conjunction. These paths are combined with the logical 'OR' ( + sign). The single cases that are explained by this solution, the consistency and coverage indicators for the single paths and the overall solution are listed below. Cases can display several paths.

--Insert table 1 here--

In path one, a flexible instrument prevails (RESP), the issue is salient (SAL) and the country has a non-coercive interventionist style (coerc). This scenario is typical for the UK. For example, the EU's general prescription requirement does not specify which actors can issue prescriptions. This issue became salient in 2003, when a report by the UK Competition Commission found monopolies in the supply of prescription drugs (Sager et al. 2011: 272). To enhance freedom of competition, the UK administration interpreted the EU rule creatively: Besides veterinarians, other actors were granted permission to prescribe certain categories of veterinary drugs. 
In path two, flexible instruments (RESP) are customized, if the issue is both salient (SAL) and opposed (RES). One instance of this is the dispensing categories in Austria. The EU only broadly distinguishes prescription drugs from others. Austrian farmers are traditionally very influential and oppose restrictions of their freedom. In response, Austria has established a differentiated regulatory framework. The livestock owners retained an unusually generous access to veterinary drugs. However, this was coupled with information measures, educational and reporting requirements.

The third scenario entails low issue salience (sal), a high number of veto players (VPL) and a coercive interventionist style (COERC). The numerous French authorities, for example, strongly emphasize police-patrol inspections. Therefore not only livestock holders must store the documentation of administration for five years (EU rule), but veterinarians, too.

In path four, a responsive EU regulatory mode (RESP) does not fit the coercive interventionist style (COERC), combined with many veto points (VPO). One typical case is the permitted amount of drugs to be dispensed in Germany. The vague EU norm (amount needed for one treatment) clashes with Germany's remarkably coercive strategy to prevent antibiotic resistance caused by the excessive use of antibiotics. German veterinarians firmly support this strategy. The decentralized, corporatist country extensively consults stakeholders during legislation. Unsurprisingly, Germany implemented a more precise and considerably stricter solution than the EU: veterinary drugs may be dispensed for 31 days of treatment, antibiotics only for 7 days.

--Insert figure 2 here--

The solution has good consistency and coverage scores. None of the detected scenarios can 
explain why EU policies were customized extensively in 12 out of 51 cases, situated in the upper left quadrant of figure 2. There are three contradictory cases. I discuss these issues in the concluding section.

The four scenarios implying limited customization, reported in online appendix B, are not discussed in-depth, as the low solution coverage of 0.411 indicates a very limited ability to explain limited customization.

\section{Theory evaluation}

I now discuss the five hypotheses following Ragin's principles of theory evaluation (Schneider and Wagemann 2012: 295-305). The scenarios expected and those not are compared with the scenarios that were empirically (not) observed to answer three questions: first, which parts of the theory are supported by the findings? These are the areas shaded white in the tables 2 and 3 below. Second, in which direction should theory be expanded (grey areas)? Third, which parts of the theory need to be dropped (dark areas)? Online appendix C presents the underlying formal details.

--Insert table 2 here-

-- Insert table 3 here -

The first key result is that discretion matters for customization (Steunenberg and Toshkov 2009; Toshkov 2010). The presence of a flexible instrument alone is not a necessary condition for extensive customization. However, it is almost always part of the story (left part of table 
2). Flexible instruments enable the transposing countries to adapt the policy to local circumstances as necessary. The lower left quadrant of table 3 shows that responsive EU instruments are not customized when low issue salience and resistance, few veto players and a non-coercive interventionist style prevail. The picture is less clear for inflexible instruments, whose presence alone is not sufficient for limited customization, as hypothesis 2 stated (upper left quadrant of table 3), and which are still quite often customized (upper right quadrant of table 3). Inflexible instruments are typically not customized only under certain circumstances, discussed below.

Second, the results underscore the importance of domestic politics, but suggest their interplay with policy factors. Hypothesis 3 finds strong support: high numbers of veto points or players can foster the customization of strongly opposed and salient EU policies. Yet this is only the case when these policies are responsive (upper left quadrant of table 2). Results further reveal that a coercive interventionist style can replace veto points or veto players in this mechanism facilitating customization. Consider how France has dealt with the EU's permission to specify conditions for the On-Farm Manufacturing of medicated feedingstuffs (OFM). OFM is highly salient in intensive farming and fiercely contested by French veterinarians. The French government views OFM as an extremely unsafe application route. OFM is now legally allowed, however de facto impossible due to numerous administrative hurdles (Sager et al. 2014). This 'refined domestic politics' mechanism is, however, not the only path to extensive customization.

In fact, third, the countries interpret EU norms depending on their fit with their domestic style of state intervention. Yet hypothesis 4 must be differentiated according to the upper left quadrant of table 2. A misfit between a flexible EU instrument and a coercive interventionist style effectively can imply extensive customization. This is true specifically when many veto points or veto players and low issue salience prevail, as Germany's restrictive dispensing 
policy illustrates. When inflexible EU instruments clashed with a non-coercive interventionist style, policies were indeed not further customized (upper left quadrant of table 3). However, hypothesis 5 only occurred in combination with few veto players and either strong domestic resistance, or low issue salience and many veto points. One instance of the first scenario is the EU Cascade rule, which considerably restricts the possibilities to treat rare maladies and species. As Austrian veterinarians fiercely resist the Cascade rule, the Austrian administration with its non-coercive interventionist style has only adopted it to the minimum. The second scenario was encountered e.g. when the averse-to-regulation UK administration simply 'copied' the technical EU prescription form for medicated feedingstuffs. Hypothesis 5 also did not hold true in the context of high issue salience and low resistance (upper right quadrant of table 3).

The lower left quadrant of table 2 reveals two unexpected pathways to extensive customization. Countries with a non-coercive interventionist style also differentiated flexible instruments concerning salient issues. This happened when either domestic resistance was low or few veto points and players prevailed. Austria, for instance, has defined detailed conditions under which the livestock owners can pursue OFM virtually without limitations - precisely to create derogations to maintain individual freedom. Unexpectedly, even inflexible instruments were customized extensively in combination with a coercive interventionist style (path 3, table 1). The upper right quadrant of table 3 further underscores the model's limited and inconclusive explanatory power for limited customization. Clearly, the assessed compliance approaches cannot fully explain customization (lower right quadrants of tables 2 and 3).

\section{Conclusions}

The customization concept overcomes the conceptual shortcomings of the term 'gold-plating' and offers a differentiated bottom-up perspective on different ways EU member states 21 
problem-solve (Pülzl and Treib 2007). It captures how transposition results in tailor-made solutions in a multi-level system (Schmidt 2008). Despite an apparent 'no gold-plating policy' in the EU (Jans et al. 2009) and the previously stated rareness of the phenomenon (Morris 2011; Voermans 2009), results illustrate the considerable styles through which EU veterinary drugs directives are customized to fit domestic contexts. Germany, Austria, France and the UK issued market-correcting solutions that exceed the EU directive in their density or stringency (Knill et al. 2012) to secure animal health and food safety in the European single market.

This study moves EU implementation and QCA research design forward in several ways. First, the customization concept offers an alternative way to measure how much European law influences national policy-making (Töller 2010). Second, relevant factors have proven to differ between single policy issues, rather than whole directives, as units of analysis (Toshkov 2010). Third, this study expands implementation research to the veterinary drugs sector (Treib 2014). Fourth, only the interplay between both policy-specific and country-level factors has aptly illuminated how EU policy structures national policy outcomes (Sager et al. 2014; Steunenberg 2007). Fifth, the findings indicate that domestic, sectoral interventionist styles matter for transposition (Perkins and Neumayer 2007; Vedung 1998). Finally, applying formal theory evaluation to assess set-theoretic hypotheses has considerably eased the results' interpretation.

The results suggest that to a limited extent, the EU can effectively steer how far countries depart from the EU template (Knill and Lenschow 2003; Steunenberg and Toshkov 2009; Treib et al. 2007). Findings support the 'domestic politics' hypothesis that domestic interests in interaction with institutions influence transposition, but delimit its scope to the presence of flexible EU instruments and salient issues (Falkner et al. 2005; Mastenbroek 2005; Steunenberg 2007; Versluis 2003). The study thus specifies conditions under which 
institutions mediate the consideration of societal interests (Haverland 2000; Toshkov 2010). Simultaneously, I find considerable evidence that the customization of EU directives partly obeys a logic of appropriateness. The 'fit' between the styles of state intervention of the EU and the transposing countries provokes different domestic interpretations of EU directives (Mastenbroek and Kaeding 2006). This happens in interaction with domestic political and institutional factors. The findings invite for a further exploration of the relationship between different logics of action of EU member states (March and Olsen 1998).

Paradoxically, the arguments derived from compliance research have not been well suited to explain 'compliance' with the EU's 'no gold-plating' policy. To gain a better understanding of this phenomenon, deviant cases should be explored more in-depth (Schneider and Wagemann 2012). Possible explanations include EU decision-making processes (Töller 2010; Toshkov 2010), the domestic administrations' substantive preferences, and implementation and enforcement mechanisms (Treib 2014; Versluis 2003). These factors were neglected in this study. This study is based on a purposive sample of market-correcting issues that illustrate customization. It deliberately applies a modest view on generalization (Rihoux and Ragin 2009): it remains to be tested whether the present results can travel to different policies or countries.

The customization concept fruitfully sheds light on the aspect of diversity in what Majone (1999) called the 'European experience'. We evidently need to move beyond compliance (Sager et al. 2014) to gain a fuller understanding of these often neglected, more fine-grained patterns of Europeanization. Diversity is inherent in multi-level governance. More research on the causes and implications of diversity for the policies' later enforcement, application and effectiveness is needed to understand how shared policy problems are jointly resolved in the EU. 
Biographical notes: Eva Thomann is a public policy analyst at the Center of Competence for Public Management at the University of Bern, Switzerland.

Address for Correspondence: Eva Thomann, Center of Competence for Public Management, University of Bern, Schanzeneckstrasse 1, P/O Box 8573 , CH-3001 Bern, Switzerland. Email: eva.thomann@kpm.unibe.ch

\section{Acknowledgements}

Many thanks to Jonas Buche, Andreas Corcaci, Sabine Jenni, Eva Lieberherr, Ellen

Mastenbroek, Fritz Sager, Carsten Q. Schneider, all reviewers and discussants.

\section{Notes}

\footnotetext{
${ }^{1}$ As opposed to indirect legal reform requirements (Treib 2014: 23-24).

${ }^{2}$ For policies that cannot meaningfully be adopted without amendments, these numbers were slightly adapted to ensure cross-case comparability and account for fine-grained cross-country differences.

${ }^{3}$ I hereafter interpret the term 'typically' as a consistent statement of sufficiency.

${ }^{4}$ Directive 90/167/EEC was amended as the European Parliament (EP) and the European Economic and Social Committee (EESC) without exemption urged for more precise rules, additional regulations, and more detailed definitions. The EP approved Directive 2001/82/EC without amendment; the EESC recommended to adopt current technical terminology. Commission Directive 2006/130/EC did not involve stakeholders (source: Eur-
} Lex).

${ }^{5}$ Pearson's R for interventionist styles and customization restrictiveness: $0.47\left(r^{2}=0.22\right)$; COERC and CUSTOM: 
$0.30\left(r^{2}=0.092\right)$. 


\section{References}

Angelova, M., Dannwolf, T. and König, T. (2012) 'How robust are compliance findings? A research synthesis', Journal of European Public Policy 19(8): 1269-1291.

Börzel, T.A. and Risse, T. (2012) 'From Europeanisation to diffusion: introduction', West European Politics 35(1): 1-19.

Di Lucia, L. and Kronsell, A. (2010) 'The willing, the unwilling and the unable - explaining implementation of the EU Biofuels Directive', Journal of European Public Policy 17(4): 545-563.

Falkner, G., Treib, O., Hartlapp, M. and Leiber, S. (2005) Complying with Europe: EU Harmonisation and Soft Law in the Member States, New York: Cambridge University Press.

Haverland, M. (2000) 'National Adaptation to European Integration: The Importance of Institutional Veto Points', Journal of Public Policy 20(1): 83-103.

Jans, J.H., Squintani, L., Aragão, A., Macrory, R. and Wegener, B.W. (2009) “Gold plating’ of European Environmental Measures?', Journal of European Environmental Planning Law 6(4): 417- 435.

Knill, C. and Lehmkuhl, D. (2002) 'The national impact of European Union regulatory policy: Three Europeanization mechanisms', European Journal of Political Research 41(2): 255-280.

Knill, C. and Lenschow, A. (1998) 'Coping with Europe: the impact of British and German administrations on the implementation of EU environmental policy', Journal of European Public Policy 5(4): 595-614.

Knill, C. and Lenschow, A. (2003) 'Modes of regulation in the governance of the European Union: towards a comprehensive evaluation, European Integration online Papers 
7(2003-001).

Knill, C., Schulze, K. and Tosun, J. (2012) 'Regulatory Policy Outputs and Impacts:

Exploring a Complex Relationship', Regulation and Governance 6(4): 427-444.

Majone, G. (1999) 'Regulation in comparative perspective', Journal of Comparative Policy Analysis: Research and Practice 1(3): 309-324.

March, J.G. and Olsen, J.P. (1998) 'The Institutional Dynamics of International Political Orders', International Organization 52(4): 943-969.

Mastenbroek, E. (2005) 'EU compliance: Still a 'black hole'?', Journal of European Public Policy 12(6): 1103-1120.

Mastenbroek, E. and Kaeding, M. (2006) 'Europeanization Beyond the Goodness of Fit: Domestic Politics in the Forefront', Comparative European Politics 4(4): 331-354.

Morris, R. KA. (2011) 'The application of the Habitats Directive in the UK: compliance or gold plating?', Land Use Policy 28(1): 361-369.

Perkins, R. and Neumayer, E. (2007) 'Implementing multilateral environmental agreements: an analysis of EU Directives', Global Environmental Politics 7(3): 13-41.

Pülzl, H. and Treib, O. (2007) 'Implementing Public Policy’, in F. Fischer, G.J. Miller and M.S. Sidney (eds), Handbook of Public Policy Analysis: Theory, Politics, and Methods, Boca Raton, FL: CRC Press/Taylor and Francis, pp. 89-107.

Ragin, C.C. (2000) Fuzzy-Set Social Science, Chicago/London: University of Chicago Press.

Rihoux, B. and Ragin, C. (eds) (2009) Configurational comparative methods. Qualitative Comparative Analysis (QCA) and related techniques, Thousand Oaks and London: Sage.

Sager, F. (2009) 'Governance and Coercion', Political Studies 57(3): 537-558.

Sager, F., Thomann, E., Zollinger, C. and Mavrot, C. (2011) Tierarzneimittelregulierung in Europa, Study mandated by the Swiss Federal Office of Public Health. Bern, Center of Competence for Public Management. 
Sager, F., Thomann, E., Zollinger, C. and Mavrot, C. (2014) 'Confronting theories of European integration: A comparative congruence analysis of veterinary drugs regulations in five countries', Journal of Comparative Policy Analysis: Research and Practice, DOI: 10.1080/13876988.2014.960244.

Schmidt, S.K. (2008) 'Beyond Compliance: The Europeanization of Member States through Negative Integration and Legal Uncertainty', Journal of Comparative Policy Analysis: Research and Practice 10(3): 299-308.

Schneider, C.Q. and Wagemann, C. (2012) Set-Theoretic Methods for the Social Sciences. A Guide to Qualitative Comparative Analysis, New York: Cambridge University Press.

Steunenberg, B. (2007) 'A policy solution to the European Union's transposition puzzle: Interaction of interests in different domestic arenas', West European Politics 30(1): 23-49.

Steunenberg, B. and Toshkov, D. (2009) 'Comparing transposition in the 27 member states of the EU: the impact of discretion and legal fit', Journal of European Public Policy 16(7): 951-970.

Töller, A.E. (2010) 'Measuring and comparing the Europeanization of national legislation: A research note', Journal of Common Market Studies 48(2): 417-444.

Toshkov, D. (2010) 'Taking stock: a review of quantitative studies of transposition and implementation of EU law', Institute for European Integration Research, Working paper No. 01/2010.

Treib, O. (2014) 'Implementing and complying with EU governance outputs', Living Reviews in European Governance 9(1).

Treib, O., Bähr, H. and Falkner, G. (2007) 'Modes of governance: towards a conceptual clarification', Journal of European Public Policy 14(1): 1-20.

Tsebelis, G. (1995) 'Decision making in political systems: veto players in presidentialism, parliamentarism, multicameralism', British Journal of Political Science 25(3): 289- 
325.

Vedung, E. (1998) 'Policy Instruments: Typologies and Theories', in M. Bemelmans-Videc, R.C. Rist and E. Vedung (eds), Carrots, Sticks and Sermons: Policy Instruments and their Evaluation, New Brunswick and London: Transaction Publishers, pp. 21-58.

Versluis, E. (2003) Enforcement matters. Enforcement and Compliance of European Directives in Four Member States, Delft: Eburon.

Voermans, W. (2009) ‘Gold-plating and double banking: an overrated problem?’, in H. Snijders and S. Vogenauer (eds), Content and Meaning of National Law in the Context of Transnational Law, Munich: Sellier European Law Publishers, pp. 79-88. 
Table 1: Sufficient conditions for extensive customization

\begin{tabular}{|c|c|c|c|c|}
\hline Solution & RESP*SAL*coerc + & RESP*SAL*RES + & sal*VPL*COERC+ & RESP*VPO*COERC $\rightarrow$ CUSTOM \\
\hline $\begin{array}{l}\text { Single case } \\
\text { coverage }\end{array}$ & $\begin{array}{l}\mathrm{AU}: \mathrm{a} 4 \\
\mathrm{UK}: \mathrm{d} 2,6,7,10,12, \\
13, \mathbf{a} 4\end{array}$ & $\begin{array}{l}\text { AU:d2,6,7 } \\
\text { FR:d1,2,10,a4,5 } \\
\text { GE:d2,4,7,10,a4 } \\
\text { UK:d2,6,12 }\end{array}$ & $\begin{array}{l}\text { FR:d6,7,9, } \\
12,13, \mathrm{a} 1,3, \\
\text { d4,8 } \\
\text { GE:d6,12,13, a1 }\end{array}$ & $\begin{array}{l}\text { AU:d1,2,4,6,7, } \\
\text { 10,12,13 } \\
\text { GE:d1,2,4,6,7,10, } \\
12,13, \mathrm{a} 4,5\end{array}$ \\
\hline $\begin{array}{l}\text { Consistency } \\
\text { Raw coverage } \\
\text { Unique } \\
\text { coverage } \\
\text { Solution consis }\end{array}$ & $\begin{array}{l}0.887 \\
0.207 \\
0.033 \\
\text { cy: } 0.805, \text { solution }\end{array}$ & $\begin{array}{l}0.880 \\
0.344 \\
0.048 \\
\text { overage: } 0.757\end{array}$ & $\begin{array}{l}0.826 \\
0.236 \\
0.099\end{array}$ & $\begin{array}{l}0.903 \\
0.379 \\
0.076\end{array}$ \\
\hline
\end{tabular}

Bold: contradictory case. $\quad \mathrm{AU}=$ Austria, $\mathrm{FR}=$ France, GE = Germany, UK = United Kingdom Raw consistency threshold: 0.764. Next highest consistency score 0.669.

1 path omitted due to low empirical relevance (see online appendix B, table B3).

Table 2: Theory evaluation for extensive customization

\begin{tabular}{|c|c|c|}
\hline & $\begin{array}{l}\text { Empirics } \\
\text { Detected in solution }\end{array}$ & Not detected in solution \\
\hline $\begin{array}{l}\text { Expected } \\
\text { scenarios }\end{array}$ & $\begin{array}{l}\text { RESP*SAL*RES*(VPO + VPL + } \\
\text { COERC) + RESP*COERC*(VPO + } \\
\text { sal*VPL) } \\
\text { N(CUSTOM): } 27 \text { (supports theory) } \\
\text { N(custom): } 1\end{array}$ & $\begin{array}{l}\text { RESP*COERC*vpo*vpl*(sal + res })+ \\
\text { RESP*COERC } * \mathrm{SAL}^{*}{ }^{*}{ }^{*}{ }^{*} \mathrm{vpo} \\
\mathrm{N}(\mathrm{CUSTOM}): 0 \\
\mathrm{~N}(\text { custom }): 0 \text { (only >0 delimits theory) }\end{array}$ \\
\hline $\begin{array}{l}\text { Not } \\
\text { expected } \\
\text { scenarios }\end{array}$ & $\begin{array}{l}\text { RESP*SAL*coerc*(res + vpo*vpl) }+ \\
\text { resp*sal*VPL*COERC } \\
\text { N(CUSTOM): } 11 \text { (extends theory) } \\
\text { N(custom): } 2\end{array}$ & $\begin{array}{l}\text { resp*(SAL }+\mathrm{vpl}+\text { coerc) }+ \text { sal*coerc } \\
\text { N(CUSTOM): } 13 \text { (suggests overlooked } \\
\text { explanations) } \\
\text { N(custom): } 22 \text { (supports theory) }\end{array}$ \\
\hline
\end{tabular}

Based on Schneider and Wagemann (2012: 301) and table 1. Bold: Hypotheses 1, 3 and 4:

RESP*(SAL*RES*(VPO + VPL $)+$ COERC $) \rightarrow$ CUSTOM.

Table 3: Theory evaluation for limited customization

\begin{tabular}{|c|c|c|}
\hline & $\begin{array}{l}\text { Empirics } \\
\text { Detected in solution }\end{array}$ & Not detected in solution \\
\hline \multirow[t]{2}{*}{$\begin{array}{l}\text { Expected } \\
\text { scenarios }\end{array}$} & $\begin{array}{l}\text { resp*SAL*vpo*COERC + } \\
\text { resp*coerc* }^{*}\left(\mathrm{RES}^{*} \mathrm{vpl}+\mathrm{sal}{ }^{*} \mathrm{vpo}^{*} \mathrm{vpl}\right)\end{array}$ & $\begin{array}{l}\text { resp*(res*VPO + sal*VPL + sal*COERC + } \\
\text { VPO*VPL + VPO*COERC }+ \\
\text { resp*coerc*(SAL*res + VPL })\end{array}$ \\
\hline & $\begin{array}{l}\text { N(custom): } 9 \text { (supports theory) } \\
\text { N(CUSTOM): } 1\end{array}$ & $\begin{array}{l}\text { N(custom): } 10 \\
\text { N(CUSTOM): } 16 \text { (delimits theory) }\end{array}$ \\
\hline $\begin{array}{l}\text { Not } \\
\text { expected } \\
\text { scenarios }\end{array}$ & $\begin{array}{l}\text { RESP*sal*res*vpl*coerc } \\
\text { N(custom): } 4 \text { (extends theory) } \\
\text { N(CUSTOM): } 0\end{array}$ & $\begin{array}{l}\text { RESP*(RES + SAL + VPL + COERC) } \\
\text { N(custom): } 2 \text { (suggests overlooked } \\
\text { explanations) } \\
\mathrm{N}(\text { CUSTOM): } 34 \text { (supports theory) }\end{array}$ \\
\hline
\end{tabular}

Based on Schneider and Wagemann (2012: 301) and table B5. Bold: Hypotheses 2 and 5: resp + resp*coerc $\rightarrow$ custom. 
Figure 1: Country profiles

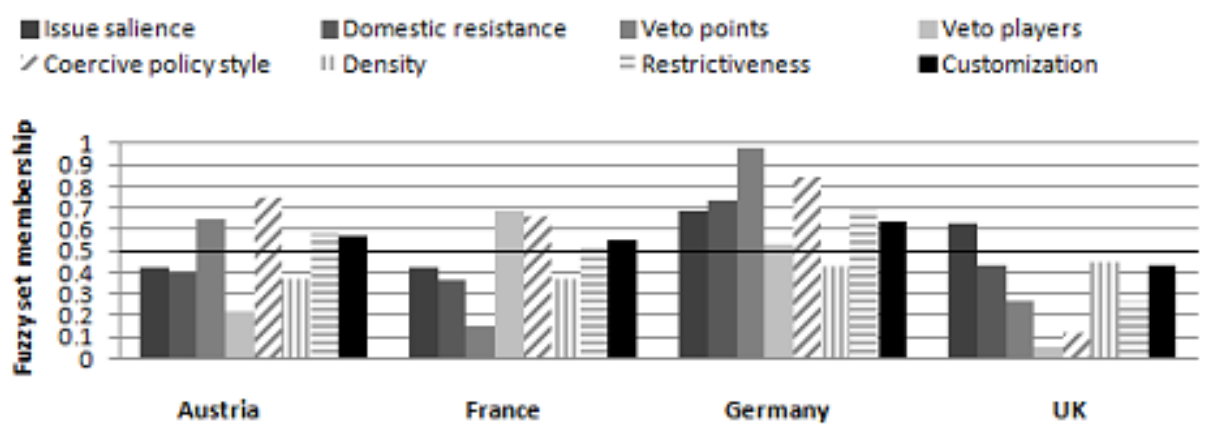

Average set membership of cases sorted by country.

$\mathrm{N}=76$.

Values above 0.5 indicate a feature's partial to full presence, values below 0.5 its partial or full absence. Density and restrictiveness scores were fitted into a scale from 0 to 1 .

Figure 2: Sufficient conditions for extensive customization

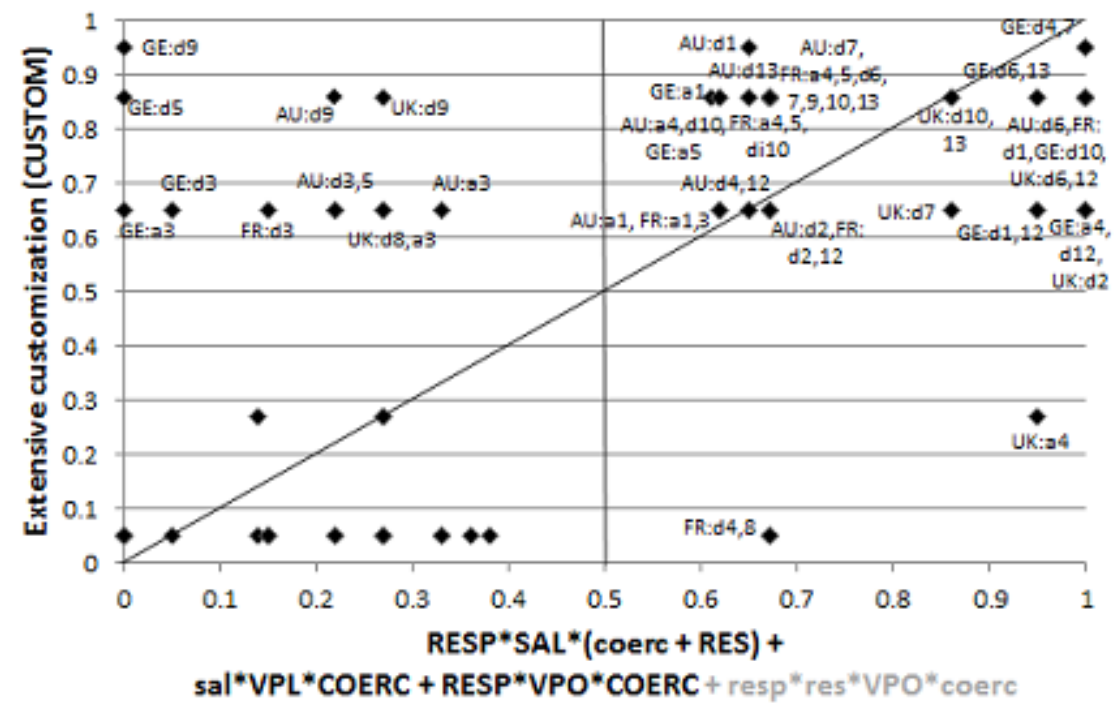

Cases situated above the diagonal are consistent. In the upper left quadrant are uncovered cases, in the lower right quadrant are contradictory cases. The lower left quadrant is irrelevant (Schneider and Wagemann 2012: 67ff, 308). 